ISBN - 978-93-86878-38-0

16th TURKEY International Conference on Industry, Law, Education and Interdisciplinary Studies

(TILEIS-2020)

Istanbul (Turkey) Mar. 2-4, 2020

\title{
Moving University Students to the Global Stage: A New Curriculum in Global Cultures
}

\author{
Gina Zanolini Morrison \\ Wilkes University, U.S.A.
}

\begin{abstract}
Universities in the United States are facing serious challenges in preparing their students for successful careers that will facilitate their positive contributions to the globalized world. With a rise in nationalism and antiimmigrant sentiment, leading to the enactment of controversial political policies regarding immigration, terrorism, foreign policy, and climate change, the U.S. is currently undergoing a critical period in its development on the world stage, yet is still viewed as one of the most important international leaders. This role mandates American universities to prepare workers, thinkers, and leaders for successful navigation within the global workforce.
\end{abstract}

To this end, one small private American university has created a flexible, interdisciplinary Global Cultures Minor to encourage students with a penchant for global citizenship to expand their global knowledge and apply it to their major disciplines. This minor was recently launched and has exceeded enrollment expectations. It is hoped that our new minor will encourage development of curricula about the global forces that contribute to the shaping of cultures, including: migration and diaspora, colonization, religion and spirituality, rights of women and children, health and poverty, privilege and class, indigenous peoples of the world, globalization, terrorism, war and trauma, trans-national cultural identities, environmental and cultural sustainability, and the arts. The curricular design of the minor and the syllabus of the newly created anchor course in global cultures issues and perspectives will be shared in this session.

Keywords: global cultures, interdisciplinary studies, global studies curriculum

\section{Introduction}

Our globalized world is in a constant state of change. Global warming, political shifts, population crises, and worldwide migrations are causing effects that are immediate and far-reaching; indeed, facing the complexity of global problems can be overwhelming and disillusioning (Seitz \& Hite, 2012). In response to these global issues, cultures constantly change, too, while clinging to the unique practices that bond their people together into a sustainable culture (Gannon \& Pillai, 2015). Understanding the organic and ever-changing nature of culture, grasping the nature of cultural studies as a self-questioning science of interpretation--even pinpointing the elusive definition of culture itself--are daunting tasks (Geertz, 2000). It is not an easy job to prepare our students for these serious challenges; yet, it is the primary responsibility of universities to do so.

The current political climate in the United States adds to that challenge for American universities, whose objective it is to prepare their students for careers as skilled, informed, and positive agents of change in the global context. With a rise in nationalism and anti-immigrant sentiment, leading to the enactment of controversial political policies regarding immigration, foreign policy, and climate change, the U.S. is currently undergoing a critical period in its development on the world stage, yet, it is still viewed as one of the most important international leaders. This role mandates American universities to prepare workers, thinkers, and leaders for successful navigation within the global workforce. 
To this end, one small, private liberal arts American university of over 5,000 students has created a flexible, interdisciplinary Global Cultures Minor. This curriculum was created within the Division of Global Cultures of Wilkes University to encourage students of any major to expand their global knowledge and apply it to their major disciplines according to their individual agenda. This minor was recently launched and has exceeded enrollment expectations. It is hoped that our new minor will encourage development of further curricula about the global forces that contribute to the shaping of cultures, such as migration and diaspora, colonization, religion and spirituality, rights of women and children, health and poverty, privilege and class, indigenous peoples of the world, terrorism, war and trauma, trans-national cultural identities, environmental and cultural sustainability, and the arts.

Therefore, an eighteen-credit Global Cultures Minor was proposed to serve as a foundation for undergraduate students with an interest in cultures and an aim to inform their major courses of study with cultural knowledge. In close consultation with the faculty Global Studies Advisor, each student can plan a coherent course of study to allow the construction of a unique, personalized curriculum leading to a focus in one global culture or a related issue, with the intention of integrating that knowledge into the student's career plans upon graduation and/or furthering knowledge in this area through formal graduate studies. The immediate success of this minor sends a message that it not only fills existing gaps in university curricula, but also that there is a rising student interest in a minor of this focus and design, which reflects central themes of the university mission and vision.

\section{Rationale}

Wilkes University, a predominantly white university, has developed a far-reaching goal of embracing diversity and developing cultural competence in its students through "exceptional educational experiences that transform students and develop innovations through scholarly activities that lead to national recognition and shape the world around us" (Wilkes University, 2020). These guiding principles reflect a sincere commitment to preparing students for success in the multicultural world. While long-term efforts to provide a welcoming environment for students of all backgrounds have been increasingly successful in recent years, as evident in the rise in student diversity, our curricular treatment of diversity has only recently begun to expand.

For example, it was only in 2016 that the faculty approved a set of diversity student learning outcomes for inclusion in the general education requirements, which was soon followed by the addition of several topic courses on diversity that have enhanced the student interest in global cultures. Foreign languages in particular have increased, as have courses on Asian history and modernity, courses on global trends in energy and ethics, and courses that include faculty-led study abroad trips to destinations in Africa, South America, Europe, and Asia. Further, faculty have noted the benefits of new programs on sustainability and energy, as well as a robust women and gender studies minor.

Nevertheless, campus curricular offerings in areas that embrace the university's mission of "liberally educating our students for lifelong and success in a constantly evolving and multicultural world" (Wilkes University, 2020) are scattered throughout the campus, leaving few options for students who wish to study cultures affected by current global trends in a coherent manner. Thus, it was felt that our proposal to create a flexible Global Studies Minor would provide not only a platform for building the global knowledge and cultural competency skills of all its graduates, but also a foundation for future growth and life-long learning. Indeed, it doing so, it also integrates the university's core values of scholarship, diversity and innovation.

Nothing is more important to the future of this planet than preparing students to become informed and ethical instruments of positive global and cultural engagement. Empowered with knowledge about global history, systems, forces, and trends of cultures, and armed with major-specific skills, Global Cultures Minors will be positioned to understand their multicultural world, to act ethically and effectively within it, and to identify what further study is needed to become leaders on the global level within their respective disciplines. 
In addition, this program increases employability within international job markets by providing specialized preparation useful for careers in governmental and non-governmental agencies; health care; businesses and multi-national companies in the United States and the international community; social services in multi-ethnic environments (including criminology and immigration law); teaching or service in multi-ethnic, private, or international schools; global journalism; cross-cultural psychology; and careers involving international research in STEM fields. As an interdisciplinary minor, it is flexible in that it may be added to any major course of study to show the student's concern with and interest in cultures and the global forces that affect them. This adds a dimension of useful knowledge that will be attractive to future employers and institutions of higher learning.

It is hoped that the Global Cultures Minor will encourage the development of more courses such as AfricanAmerican cultures and literature, Latino studies, Asian cultures, indigenous peoples of the world, and other topics reflecting trans-national cultural identities and related global issues. Also, it is anticipated that it will encourage the development of - and institutional support of - many study-abroad options for the students.

\section{Program Design}

The minor was designed to help students broaden their interests and expand their knowledge by taking courses in any number of disciplines. With one anchor course (GC 301-Global Cultures: Issues and Perspectives) and another requirement of a foreign language of any level, students are required to sign up for courses otherwise omitted from their majors; thus, the creation of this minor has the potential to populate courses in many other divisions on this campus, bringing students with interdisciplinary interest in the topic, knowledge of cultures and global trends, and a penchant for global citizenship.

This interdisciplinary minor provides flexibility for students to choose their courses, as long as each student takes the anchor course (GC 301). Students must take five more courses from a faculty-approved list of courses, and one of those must be a foreign language. More courses can be added to the list at any time upon request, if approved by a syllabi review conducted by the faculty of the Division of Global Courses, with the input of faculty in other divisions as appropriate, and ultimately approved by the university Curriculum Committee. Courses may be taken in any order, with the strong recommendation that GC 301 should not be taken during the student's first year. Again, a major component of this Global Cultures Minor is the mentorship of the Global Cultures Minor Advisor and the close consultation that will be needed for advisor and student to work together to shape a unique curricular path, in accordance with each student's focus.

\section{Assessment}

\subsection{Student Learning Outcomes.}

To guide the curricular design, the faculty leaned heavily on an accepted Global Learning Rubric developed by the American Association of Colleges and Universities (AAC\&U, 2020). This rubric explains:

Global learning is a critical analysis of and an engagement with complex, interdependent global systems and legacies (such as natural, physical, social, cultural, economic, and political) and their implications for people's lives and the earth's sustainability. Through global learning, students should 1) become informed, open-minded, and responsible people who are attentive to diversity across the spectrum of differences, 2) seek to understand how their actions affect both local and global communities, and 3) address the world's most pressing and enduring issues collaboratively and equitably.

In the context of building each student's foundation of knowledge regarding global cultures, then, throughout the curriculum faculty address and assess the development of six constructs of understanding related to Global Cultures, as recommended by the AAC\&U Global Learning Rubric:

(1) Global Self-Awareness

(2) Perspective Taking

(3) Cultural Diversity

(4) Personal \& Social Responsibility

(5) Understanding Global Systems 
(6) Applying Knowledge to Contemporary Global Contexts

Therefore, upon completion of the Global Cultures Minor, students will have demonstrated competency in each of the above areas, as assessed by a ranking of at least a 3 out of 4 on the AAC\&U Global Learning Rubric in a variety of assignments, one from each course throughout the required course curriculum.

\subsection{Measurement of Student Learning Outcomes}

One of the key components to the curricular design of this minor is the close consultation that must occur within the students and the Global Cultures Advisor in order to create the student's unique path of study according to her/his focus. The resulting portfolio of evaluated assignments over the course of the program will be reviewed by Advisor before graduation. Together, these assignments will create an assessment portfolio of evidence that competency has been met for each of the above constructs. Therefore, each student's assessment portfolio will be as unique as the focus and design of the curriculum that has been constructed.

\subsection{External Accreditation Agencies}

Although the Global Learning Value Rubric developed by AACU is used to guide the structure and the assessment plan for our Global Cultures Minor, there are no external accreditation agencies that will have any continued involvement in the assessment of the Global Cultures Minor after its approval.

\subsection{Syllabus Components of the anchor course, Global Cultures: Issues and Perspectives}

1) COURSE DESCRIPTION: A broad interdisciplinary introduction to the issues and theory underlying the study of global cultures, this course will address the global forces that contribute to the shaping of cultures, including: migration and diaspora, colonization, religion and spirituality, rights of women and children, health and poverty, privilege and class, indigenous peoples of the world, globalization, terrorism, war and trauma, environmental and cultural sustainability, cultural identity development, and the arts. Particular attention will be given to ethics and global citizenship. This course will serve as a foundation for students in choosing to further their studies in one global culture or issue of interest, in order to integrate this knowledge into their future careers.

2) REQUIRED READINGS: Students read excerpts from the following works, with the understanding that there may be additional articles or short readings provided online:

Gannon, M. J. \& Pillai, R. (2015). Understanding global cultures: Metaphorical journeys through 34 nations, clusters of nations, continents, and diversity ( $6^{\text {th }}$ ed.). Thousand Oaks, CA: Sage Publications. ISBN 978-1-4833-4007-4.

Geertz, C. (2017). The interpretation of cultures. NY: Basic Books. ISBN 978-0-465-09355-7.

Kipling, R. (1886). Lispeth. First published in the Civil and Military Gazette. Available online at: https://americanliterature.com/author/rudyard-kipling/short-story/lispeth

McIntosh, P. (1989). White privilege: Unpacking the invisible knapsack. Peace and Freedom (7/8). Available online at: https://www.elsalvadorsolidarity.org/wp-content/uploads/2018/06/White-Privilege_McIntosh-1989.pdf

Miner, H. (1956). Body ritual among the Nacirema. American Anthropologist, 58(3), 503-507. Available at https://www.sfu.ca/ palys/Miner-1956-BodyRitualAmongTheNacirema.pdf .

Seitz, J. L. \& Hite, K. A. (2012). Global Issues: An Introduction ( $4^{\text {th }}$ ed.). Malden, MA: Wiley-Blackwell. ISBN 978-0470-65564-1.

3) COURSE OBJECTIVES: This course will provide the students with opportunities to prepare for success in the modern world of globalization and diversity. Therefore, upon completion of the course, students will be able to:

1. Demonstrate the ability to read, research, reflect upon, synthesize and share basic content knowledge of the trends, forces, and systems of globalization, and how they have influenced the cultures of the world.

2. Write with skill to express critical thinking about ethical issues involved in globalization. 
3. Identify the stages of cultural identity development and reflect upon one's own cultural identity as part of a global, interconnected world.

4. Compare various cultures and explore ways to accept and embrace differences within a pluralistic global society. This includes knowledge of multiple worldviews and an articulation of multiple perspectives.

5. Integrate core knowledge about Global Cultures and discipline-related content knowledge in preparation for a program or initiative of ethical and sustainable global change.

6. Articulate the ways in which new knowledge, discoveries, history, culture and traditions, events, societal influences, political changes, globalization processes, and personal experience can lead an individual to address complex global problems through a cross-cultural and interdisciplinary approach to change.

7. Relate career development to this learning experience by articulating how this new knowledge has the potential to shape one's own career path.

8. Address global citizenship by reflecting upon the ways in which this learning experience has enriched not only one's personal and academic growth, but also ethical development as agents of positive change in a richly diverse, ever-changing, modern and spiritual world, with the ultimate goal of developing a personal definition of global citizenship.

4) COURSE REQUIREMENTS: In order to meet course objectives, students are expected to complete the following:

1. Readings: Students should read the assigned book chapters, articles, and other materials distributed by the instructor, in advance of the class. Note: Students should allow extra time to read and digest the material, which might be unfamiliar, so that class time can be used to construct knowledge and understanding together. (Readings are assessed by tests, which account for $20 \%$ of the final course grade, as clarified in the next item.) *Course Objectives addressed: 1,4 .

2. Tests. Students will be assessed on the reading and lecture materials throughout the semester, in order to ensure that the material is covered at a level sufficient to generate meaningful discussion during the class periods. Grades from tests and/or other assessments (such as optional tutorials) will account for $20 \%$ of the final grade. ${ }^{*}$ Course Objectives addressed: $1,4$.

3. Participation and Professionalism: This course is designed to construct new knowledge through the process of sharing information. Therefore, students should plan to attend all class sessions and participate in classroom activities, which will include short, informal presentations on assigned topics. Class time will be utilized to generate possible activities that might be undertaken to combat some of the global issues that are currently impacting our world in a negative way. As ethical agents of change, students should come to class prepared for active and informed engagement by reading all assigned work in advance of every class. Punctuality and active participation are necessary to ensure that students will be able to process the issues covered in this class. In addition, please demonstrate professionalism whenever representing this class and Wilkes University at out-ofclass events that might be scheduled, such as field trips, special lectures, conferences, or performances. Participation and professionalism will account for $20 \%$ of the final course grade. ${ }^{*}$ Course Objectives addressed: 1 , $4,6$.

4. Online Discussions and Journal Reflections: Students will respond to reading assignments, course activities, and prompts with brief, informal writings. Journals and discussions will be submitted online in LIVE and collectively will account for $20 \%$ of the final course grade. *Course Objectives addressed: 1-8.

5. Research Group Annotated Bibliography. Students will be placed into Research Groups to assist the process of discovering and discussing the most important scholarly contributions in your field of study, with each person contributing to the process in appropriate ways. It is hoped that this group effort will help support you in your Proposal and Defense, described below. The effectiveness of your Research Group will be assessed by the quality of the Annotated Bibliography, one per group, from which you will draw your own sources as needed, and which will account for $20 \%$ of the final course grade. *Course Objectives assessed: 1, 2, 5 and 7.

6. Proposal and Defense. After topics of interest have been identified and explored, a particular focus on a culture or global issue will be developed by each student in consultation with the instructor. Each student is required to develop a proposal to conduct some future course of action, such as: research project; conference paper, presentation or poster; grant application; artistic project plan. Your Proposal should be submitted in the form of a well-written paper (or a completed application for some endeavor) that demonstrates effective synthesis of a semester-long investigation into one aspect of global cultures and/or related issues, and it must demonstrate a clear plan to carry out the project in the future. Each student will also deliver an oral presentation of the Proposal in a 
Defense to the class. The written Proposal with the oral Defense, together, are worth $20 \%$ of the final course grade. Rubrics will be provided. *Course Objectives addressed:1- 8.

* Important Note: Students must work with the Global Cultures Advisor to be sure that the necessary assignments have been assessed and included in the Global Culture Assessment Portfolio.

5) GRADING. Each student has the possibility of earning a total of 100 points in this course. Points can be earned in the following ways:

\begin{tabular}{lc} 
Participation \& Professionalism & 20 \\
Journal Reflections \& Discussions & 20 \\
Tests & 20 \\
Research Group Annotated Bibliography & 20 \\
Proposal \& Defense & 20 \\
\hline Total: & 100 points
\end{tabular}

Final grades will be determined according to the following point value system:

$$
\begin{array}{llll}
4.0(\mathrm{~A}) & =94-100 \text { points } 2.0(\mathrm{C}) & =70-74 \text { points } \\
3.5(\mathrm{~A}-\mathrm{B}+) & =87-93 \text { points } 1.5(\mathrm{C}-/ \mathrm{D}+) & =64-69 \text { points } \\
3.0(\mathrm{~B}) & =80-86 \text { points } 1.0(\mathrm{D}) & =60-63 \text { points } \\
2.5(\mathrm{~B}-/ \mathrm{C}+) & =75-79 \text { points } & 0.0(\mathrm{~F}) & =0-59 \text { points }
\end{array}
$$

6) COURSE ASSESSMENT: The Global Cultures Minor requires students to assemble a portfolio of graded assignments, which are evaluated according to the Global Learning Rubric (AAC\&U). The assessment of all course assignments in this course, which is the anchor course in the Global Cultures Minor, will be guided by the Global Learning Rubric, attached to the syllabus.

\section{Conclusion}

Through the mentorship and personalized attention included in this Global Cultures curriculum, it is feasible to move university students to the global stage. Of course, it is impossible to impart knowledge on every culture and every issue affecting them on this earth; however, "It is not necessary to know everything to understand something" (Geertz, 2000, p. 22). Therefore, it is hoped that the description of this flexible, interdisciplinary Global Cultures Minor might provide a possible structure for other small universities that struggle to support their students' drive to excel in their content areas, while developing skills that will prove useful-if not crucial - to the broader, global community-at-large.

\section{Acknowledgements}

Thank you to the members of the Division of Global Cultures of Wilkes University for supporting and assisting the development of this interdisciplinary minor.

\section{References}

[1] AAC\&U (2020). American Association of University Global Learning Value Rubric. Retrieved 17 February 2020 from https://www.aacu.org/value/rubrics/global-learning

[2] Gannon, M. J. \& Pillai, R. (2015). Understanding global cultures: Metaphorical journeys through 34 nations, clusters of nations, continents, and diversity ( $6^{\text {th }}$ ed.). Thousand Oaks, CA: Sage Publications. ISBN 978-1-4833-4007-4.

[3] Geertz, C. (2017). The interpretation of cultures. NY: Basic Books. ISBN 978-0-465-09355-7.

[4] Seitz, J. L. \& Hite, K. A. (2012). Global Issues: An Introduction (4 ${ }^{\text {th }}$ ed.). Malden, MA: Wiley-Blackwell. ISBN 9780-470-65564-1.

[5] Wilkes University (2020). Mission \& Vision Statement. Retrieved 17 February 2020 from https://www.wilkes.edu/campus-life/student-development/civic-engagement/mission-vision.aspx 